\title{
THE FEDERAL ANTI-BIOTERRORISM FUNDS: A POTENTIAL CATALYST FOR COOPERATION
}

\author{
Thomas Rosenquist \\ Vice Chancellor for Research \\ University of Nebraska Medical Center
}

Consistent with the general theme of this year's meeting, "Science at a Time of National Emergency," I wish to consider first that the current emergency is different from our previous experiences with crises that have impinged upon, and changed, research activities in a given laboratory or institution. In the past, resources may have been reduced, and research activity consequently limited; or, a threat may have arisen in society that demanded a reallocation of a constant level of resources, and in response, investigators may have altered the direction of their work while maintaining their typical scale of work. Most senior investigators today have experienced, and have responded to, both of these kinds of crises. The current crisis is different from either of the above. The real threat of biological, chemical and explosive terrorism has resulted in a simultaneous increase in research funding, and a demand for reallocation of effort.

Individual investigators and research institutions as a whole are likely to address this crisis by doing more research, and by addressing the specific problems of terrorism through a change in the direction of their research. It therefore is a time of both danger and opportunity, consistent with the Chinese symbols that together mean "crisis." Indeed, while it is the duty of the great universities at this meeting to apply the strength of their research enterprise to help protect the people of the United States, simultaneously it is our duty as research administrators to gain our appropriate share of these newly allocated resources. So, the question is, what resources have been made available, who has them, and how do we get them?

At this time, there are no well-defined answers to these questions. It is obvious that the government of the United States will be allocating several billions of dollars to the current anti-terrorism mission, and that these funds will be distributed widely among the myriad of federal departments and their constituent agencies. Major distributions of anti-terrorism funds will be carried out by the Departments of Defense, Agriculture, and Health and Human Services; and we, the research universities, have both the experience with these agencies and the research expertise to address these new sources effectively. Our best strategy for doing so will include our collaboration. The heartland state universities at this meeting can produce critical masses of scientists to compete effectively with the coastal giants for these (and all other) research funds - if we can overcome our parochialism, political boundaries that inappropriately limit 
intellectual sharing, and concerns about which university or politician will get "credit" for any successes.

Indeed, each year at this meeting we discuss ways to establish a functional cooperative network of scientific investigation among the Big Square States of lowa, Kansas, Missouri and Nebraska, that will help us establish critical masses and larger scales to improve our position nationally. In 1999, Charlotte Bronson of lowa State University gave a wonderful summary of the benefits of cross-university linkages and the problems inherent in their establishment. The benefits she described are perfectly suited to the current crisis, and to our proposal for seizing this opportunity for funding: highly coordinated research that is synergistic and free from duplication, operating on a scale beyond the reach of any of us acting alone, and the capacity to assume niches that would otherwise be available only to the Coastal Giants. Unfortunately, and certainly not to our credit as administrators, the limiting conditions she described are still with us.

At the same meeting, Bruce Harmon of lowa State University was a strong advocate of the need to establish a functional inter-institutional science network among us, and suggested that a goal of this network should be to address the 1999 priority areas of the National Science and Technology Council, including: global change; emerging infectious diseases; protecting against twenty-first century threats; aviation safety and security; and food safety. The prescience of this list - its obvious relevance to the current crisis - is breathtaking. If we had listened to Drs. Bronson and Harmon, by now we would be well situated to address the current crisis. But we didn't. So, how do we proceed from here?

I would like to use the states of Kansas and Nebraska (fraternal, not identical, twins) to illustrate some potential synergies that might be used to meet the challenges of the present crisis. Data prepared by the National Science Foundation Division of Science Resources Statistics show that Nebraska and Kansas each do poorly overall in federal funding. If dollars flowing out of a state are in balance with those flowing into that state, then its rank among the states in a given federal funding category should be about the same as its population rank; thus, for Kansas a rank of 33 is neutral and for Nebraska, 39. By this approximation, Kansas is in negative territory (rank worse than 33) for $7 / 10$ of major federal funding sources, and Nebraska is negative (rank worse than 39) for $8 / 10$. Both states clearly need help; each may be able to help the other. Kansas is disproportionately well funded from the Department of Defense (rank of +6 ) and Nebraska is quite low (-8); whereas, Nebraska is disproportionately well funded from the Department of Agriculture (+21) and Kansas is low (-4). Thus, researchers in Kansas might expand their Defense-funded research by utilizing the reservoir of NU investigators; and conversely, Nebraskans may provide the backbone for Agriculture. There are other, better examples I'm sure, and this principle can be applied more widely among all of the Big Square States in the Middle, i.e., the principle that each of us has special expertise that can be applied to the good of all of us, if we can get smarter and more generous. 
Are there ways the universities from the Big Square States may help each other, share expertise, develop synergies, and grow to be more competitive for federal research funding? Obviously. Will we do so? Let us say that we should, and that we can. It is easier said than done, but embedded within the current crisis is the opportunity for substantial gain in our research enterprise, if we, the research leaders among the universities, take the lead in overcoming the restraints, including parochialism and political boundaries, that inappropriately limit intellectual sharing, and concerns about which university or politician will get "credit" for any successes - as discussed above.

Strategies for developing inter-university collaborations among the attendants at this meeting clearly is not a new topic, and I haven't discovered any new and exciting strategies that will be sure to work. However, the current crisis is new and significant, and should induce our serious consideration of the old strategies, such as: inform our respective investigators about the value of collaboration; develop appropriate incentives; dedicate ourselves to educating our university presidents, boards, state legislators, and federal representatives about the advantages of playing nicely together. We need to get together, form a coalition that works, and get some "anti-terrorism" funding that we couldn't have attracted without working together. With this example, we will have the basis for more, bigger, better research based upon new critical masses. 